\title{
ZUR HOCHKONJUNKTUR DES "CHRISTLICHEN ABENDLANDES« IN DER WESTDEUTSCHEN GESCHICHTSSCHREIBUNG
}

$\mathrm{Da}$ wohl niemals vorher und nachher in der neueren deutschen Geschichte so viel vom "Abendland «, häufig mit der näheren Charakterisierung als "christliches Abendland«, die Rede war, wie nach dem Zweiten Weltkrieg in den Westzonen ${ }^{1}$ und der frühen Bundesrepublik, ist mittlerweile von der Zeitgeschichtsforschung ausführlich mit den dafür zu nennenden Gründen dargestellt worden ${ }^{2}$. Die vage Assoziationsbreite der recht verschieden bestimmbaren kulturphilosophischen und politischen Abendland-Begrifflichkeit aktivierte ein breites Spektrum von diffusen Vorstellungen hochkultureller Inhalte, bei humanistisch Gebildeten auch der Besinnung auf das Verhältnis von Hellas und Hesperien, bis zum Verständnis des "Abendlandes« als allgemeinem Haltepunkt im Krisenbewußtsein nach nationalistischem Rausch. In der »Schulddebatte« um die Ursachen für das "Dritte Reich» erwies sich die Anrufung des "Abendlandes« als kongenial geeignet für die Vernebelung konkreter Verantwortlichkeit, ein attraktives Angebot für den weltanschaulichen Komfort weiter Teile der nationalsozialistisch belasteten Eliten. Die Abwendung von Gott - spätestens seit der Renaissance -, eine sich steigernde Säkularisierung in Gestalt von Rationalisierung und Technisierung, habe ein weltanschauliches Vakuum des Nihilismus geschaffen, in das gefährliche Dämonen einbrechen konnten. Mit diesem christlich-konservativen Narrativ, das nicht nur im Umkreis der beiden großen Kirchen formuliert wurde, konnte die Moderne auf die Anklagebank gesetzt werden und mußte für die Gegenwart eine christliche renovatio als einziger Ausweg erscheinen. Dabei wurde immer wieder tröstlich bemerkt, daß ein gesunder Kern abendländischen

1 Vgl. Dieter FELBICK, Schlagwörter der Nachkriegszeit 1945-1949, Berlin, New York 2003, S. 104ff.

2 Vgl. Axel SCHILDT, Zwischen Abendland und Amerika. Studien zur westdeutschen Ideenlandschaft der 50er Jahre, München 1999, S. 22ff. (dort auch Hinweise zur älteren Literatur); Dagmar PöPPING, Abendland. Christliche Akademiker und die Utopie der Antimoderne 1900-1945, Berlin 2002; Vanessa CONZE, Das Europa der Deutschen. Ideen von Europa in Deutschland zwischen Reichstradition und Westorientierung (1920-1970), München 2005. 
Denkens auch dem nationalsozialistischen Totalitarismus widerstanden habe, an dem wieder angeknüpft werden könne.

Den Bezirk zerknirschter Suche nach religiöser Läuterung - das literarische Leben und die Geisteswissenschaften von der Altphilologie bis hin zur Romanistik halten zahlreiche Beispiele bereit ${ }^{3}$ - verließ die Begrifflichkeit des Abendlandes spätestens mit dem offenen Ausbruch des Kalten Krieges. Allerdings war die damit verbundene Politisierung bereits in der Schulddebatte angelegt gewesen. Denn nach der Niederlage des Dämonen Hitler war ein zweiter und gefährlicherer, Stalin, geblieben. Die weltpolitische Lage ließ es zwingend erscheinen, eine abendländische Kampffront gegen den »Bolschewismus « des Ostens zu formen, die - unter dem militärischen Schutzschild und mit der ökonomischen Unterstützung der USA - die westeuropäischen Völker vereinen sollte. Nicht vom Gegensatz zwischen Stalinismus und Demokratie war um 1950 meist die Rede, sondern von der - in abendländischer Verantwortung vor Gott gebundenen - Freiheit gegen den kollektivistischen "Bolschewismus«. Darin erneuerte sich zum einen konservative Hegemonie nach der Blamage des illusionären Bündnisses mit dem Nationalsozialismus ${ }^{4}$; zum anderen drückte der Bezug auf das »christliche Abendland«, der in der frühen Bundesrepublik in kaum einer Regierungserklärung fehlte ${ }^{5}$, eine zentrale realpolitische Einsicht aus. Deutsche Politik konnte nach dem Zweiten Weltkrieg nur in supranationaler Perspektive erfolgreich betrieben werden, durch die Einordnung in die westliche Weltwirtschaft und das westliche Militärbündnis. Der Betonung abendländischer Werte kam dabei die Funktion zu, die dominierende kulturelle Abneigung gegen amerikanische »Seelenlosigkeit « und westlichen Liberalismus - in Analogie des Verhältnisses von antikem Griechenland und Rom - zu konzedieren und gleichzeitig die Westoption gegen den BBolschewismus« als existentielle politische Notwendigkeit er-

3 Frank-Lothar KROLL, Kultur, Bildung und Wissenschaft im 20. Jahrhundert, München 2003, S. 34, 87f.

4 Axel SCHILDT, Konservatismus in Deutschland. Von den Anfängen im 18. Jahrhundert bis zur Gegenwart, München 1998, S. $211 \mathrm{ff}$; aus der Perspektive expliziter konservativer Selbstverständigung vgl. die Einleitung von Frank-Lothar KROLL (Hg.), Die kupierte Altemative. Konservatismus in Deutschland nach 1945, Berlin 2005, S. 3ff.; vgl, allgemein auch Jan-Wemer MÜLLER (Hg.), German Ideologies since 1945. Studies in the Political Thought and Culture of the Bonn Republic, New York u.a. 2003.

5 Vgl. Anneliese POPPINGA, Konrad Adenauer. Geschichtsverständnis, Weltanschauung und politische Praxis, Stuttgart ${ }^{2} 1975$; Konrad ADENAUER, "Seid wach für die kommenden Jahre«. Grundsätze, Erfahrungen, Einsichten, hg. von Anneliese POPPINGA, BergischGladbach 1997; Michael BosCH, Ideelle Aspekte der Westintegration der Bundesrepublik bei Konrad Adenauer, in: Jürgen HEIDEKING u.a. (Hg.), Wege in die Zeitgeschichte. Festschrift zum 65. Geburtstag von Gerhard Schulz, Berlin, New York 1989, S. 182-195, hier S. 184ff.; Ulrich VON HEHL, Konfessionelle Irritationen in der frühen Bundesrepublik, in: Historisch-politische Mitteilungen. Archiv für christlich-demokratische Politik (HPM) 6 (1999), S. 167-187. 
scheinen zu lassen. Daß der tatsächliche Verlauf der Geschichte, der Übergang $\mathrm{zu}$ einer westlichen Konsumgesellschaft mit einer liberalen politischen Kultur, den Zielen der Protagonisten eines »christlichen Abendlandes « keineswegs entsprach, ist bisweilen als Hegelsche »List der Geschichte« bezeichnet worden ${ }^{6}$.

Einen spezifischen Kern innerhalb der allgemeinen Abendland-Konjunktur bildeten antipreußisch orientierte, vor allem in katholischen Regionen verankerte Kreise, denen neben der bereits erwähnten westeuropäischen Supranationalität eine innenpolitische Ordnung vorschwebte, die föderale und ständestaatliche Elemente betonten und Skepsis gegenüber der im Grundgesetz fixierten parlamentarischen Demokratie formulierten. Als utopische Vision spukte hier mitunter die Wiederherstellung des mittelalterlichen sacrum imperium herum. Diese abendländische Bewegung 7 sammelte sich um die Zeitschrift »Neues Abendland « (1946-1958), die Propagandaorganisation "Abendländische Aktion" (1950-1952) und die alljährlichen Treffen der "Abendländischen Akademie « in der mittelfränkischen Bischofsstadt Eichstätt (1952-1956 und 1961-1965), zu denen sich prominente Mitglieder der CDU/CSU, der Deutschen Partei, oberste Richter, kirchliche Würdenträger und konservative Intellektuelle mit Sponsoren aus grundbesitzendem Adel und Unternehmertum trafen. Die abendländische Bewegung, obgleich katholisch grundiert, betonte ihren überkonfessionellen Charakter, vor allem einige extrem konservative Lutheraner wurden demonstrativ einbezogen ${ }^{8}$.

Darüber hinaus ist zu betonen, daß der Begriff des »Abendlandes« nach $1945 \mathrm{zu}$ einem zentralen konservativen Topos auch im protestantischen Raum

6 Vgl. für den ideengeschichtlichen Zusammenhang Axel SCHILDT, Westlich, demokratisch. Deutschland und die westlichen Demokratien im 20. Jahrhundert, in: Anselm DOERNG-MANTEUFFEL (Hg.), Strukturmerkmale der deutschen Geschichte des 20. Jahrhunderts, München 2006, S. 225-239; Michael HOCHGESCHWENDER, Was ist der Westen? Zur Ideengeschichte eines politischen Konstrukts, in: HPM 11 (2004), S. 1-30.

7 Vgl. neben der in Anm. 2 genannten Literatur Rudolf UERTZ, Konservative Kulturkritik in der frühen Bundesrepublik. Die Abendländische Akademie in Eichstätt, 1952-1956, in: HPM 8 (2001), S. 45-71; Vanessa PLICHTA (= Vanessa CONZE), „Die Emeuerung des Abendlandes wird die Emeuerung des Reiches sein«. Europaideen in der Zeitschrift "Neues Abendland « (1946-1958), in: Michel GRUNEWALD (Hg. in Zusammenarbeit mit Hans Manfred BOCK), Der Europadiskurs in den deutschen Zeitschriften (1945-1955), Bern u.a. 2001, S. 319-343; im Blick auf die Literaturszene Stephen BroCKMANN, Germany as Occident at the Zero Hour, in: German Studies Review 25 (2002), S. 477-496; aus explizit konservativer Sicht Felix DIRSCH, Individualisierung und Traditionsbewahrung. Das katholische Milieu der 1950er Jahre und die Zeitschrift »Neues Abendland«, in: KROLL (Hg.), Kupierte Alternative (wie Anm. 4), S. 101-124; Jens NORDALM, Zur Abendland-Diskussion in der frühen Bundesrepublik, in: Andreas MICHLER ( $\mathrm{Hg}$.), Blicke auf Europa: Kontinuität und Wandel, Neuwied 2003, S. 199-213.

8 Axel SCHILDT, Ökumene wider den Liberalismus. Zum politischen Engagement konservativer protestantischer Theologen im Umkreis der Abendländischen Akademie, in: Thomas SAUER (Hg.), Katholiken und Protestanten in den Aufbaujahren der Bundesrepublik, Stuttgart 2001, S. 187-205. 
avancierte. Der vormals konservativ-revolutionäre Ideologe des legendären Tat-Kreises, Hans Zehrer, forderte nach 1945 in zahlreichen Leitartikeln des "Sonntagsblatts«, die Schuld anzuerkennen, den Weg des Abendlandes verlassen zu haben. Erst durch Anerkennung dieser Schuld, so Zehrer, könne sich wieder das »Herrenbewußtsein« einer »Elite« bilden ${ }^{9}$. Als einflußreicher Vordenker muß der Soziologe Hans Freyer benannt werden, der 1931 noch eine "Revolution von rechts« propagiert hatte, und nun, 1948, die Konstruktion eines sich auf seine abendländischen Wurzeln besinnenden Europas vorstellte, das sich mit den USA gegen den Bolschewismus wenden müsse. In seinem voluminösen Werk reflektierte Freyer in dem von ihm bekannten Pathos der Nüchternheit die neuen weltpolitischen Rahmenbedingungen - nach 1945 sei alles anders geworden, begegnete sich das Abendland außerhalb Europas nicht mehr sich selbst, sondern außereuropäischen Mächten -, aber gleichzeitig wird bei der Lektüre deutlich, wie wenig hinsichtlich der Feindbestimmung geändert werden mußte ${ }^{10}$.

Gemeinhin wird unterschätzt, wie präsent die Abendland-Begrifflichkeit im Zweiten Weltkrieg, vor allem nach der Wende von Stalingrad, gewesen war; Goebbels' Durchhalte-Rede im Sportpalast vom 18. Februar 1943 und die Werbung für die Waffen-SS unterschieden sich hinsichtlich ihrer antibolschewistischen Terminologie kaum von Verlautbarungen der Kirchenführer beider Konfessionen sowie von Stellungnahmen namhafter Persönlichkeiten des Widerstands. Eben dieser Umstand trug sicherlich nach 1945 zur Popularität der Begriffswelt bei, auf die man sich von ganz verschiedenen Traditionen und politischen Positionen kommend beziehen konnte ${ }^{13}$.

Die Konjunktur der Abendland-Ideologie dauerte etwa ein Jahrzehnt. Als symbolischer Höhe- und Endpunkt mag der 10. Juli 1955 angesehen werden,

9 Hans ZEHRER, Stille vor dem Sturm. Aufsätze zur Zeit, Hamburg 1949, S. 12ff.; vgl. Axel SCHILDT, Deutschlands Platz in einem »christlichen Abendland «. Konservative Publizisten aus dem Tat-Kreis in der Kriegs- und Nachkriegszeit, in: Thomas KOEBNER u.a. (Hg.), Deutschland nach Hitler. Zukunftspläne im Exil und aus der Besatzungszeit, Opladen 1987, S. 344-369.

10 Hans FREYER, Weltgeschichte Europas, 2 Bde., Wiesbaden 1948; gleich zu Beginn wird hier »Europa« synonym zu »Abendland« verwandt (Bd. I, S. IX).

"Eine Fülle von Hinweisen dazu in: Hans-Erich VolKMaNN (Hg.), Das Rußlandbild im Dritten Reich, Köln u.a. 1994 (hier auch einschlägige Beiträge zu den beiden Kirchen); vgl. zur Reichstagsrede von Hitler am 11.12.1941 Max DOMARUS, Hitler. Reden und Proklamationen 1932-1945. Kommentiert von einem deutschen Zeitgenossen, Bd. II/2. Halbband, Wiesbaden 1973, S. 1796; zum »Abendland « in Goebbels' Sportpalastrede am 18.2.1943: Helmut HEIBER (Hg.), Goebbels-Reden, Bd. 2: 1939-1945, Düsseldorf 1972, S. 172-208; zur antibolschewistischen Abendlandvision im Widerstand: Gregor SCHÖLLGEN, Ulrich von Hassell 1881-1944. Ein Konservativer in der Opposition, München 1990, S. 140; vgl. insgesamt Hans Mommsen, Das Gesellschaftsbild und Verfassungspläne des deutschen Widerstandes, in: Hermann GRAML (Hg.), Widerstand im Dritten Reich. Probleme, Ereignisse, Gestalten, Frankfurt a.M. 1984, S. 14-92. 
als 60000 gläubige katholische und evangelische Christen im Augsburger Rosenau-Stadion sich zum Höhepunkt der Jahrtausendfeier der Schlacht auf dem Lechfeld im Jahre 955 versammelten; die vielbeachtete Hauptrede, es war sein erster öffentlicher Auftritt als Bundesaußenminister, hielt Heinrich von Brentano. Er sah eine »deutliche Parallele« zwischen der Ungarn-Schlacht vor tausend Jahren und der aktuellen politischen Lage:

Die Ähnlichkeit ist erschreckend. Damals standen vor den Toren des Abendlandes, vor den Toren dieser Stadt, in der wir weilen, die heidnischen Nomadenscharen des Ostens; Verderben und Untergang drohten. Jetzt stehen wiederum, nicht sehr viel weiter von dieser Stadt entfernt, die Massen des Ostens ${ }^{12}$.

$\mathrm{Daß}$ sich die Zeiten geändert hatten, zeigte sich an Reaktionen in der Öffentlichkeit, in der solche abendländischen Analogien als Gefährdung für erste außenpolitische Entspannungsversuche zunehmend auf kritische Stimmen stießen $^{13}$. Ein Wandel der politischen Kultur, in die der fanatische Antibolschewismus nicht mehr unangefochten paßte, war Teil der Transformation der »langen 60er Jahre« (Anselm Doering-Manteuffel).

\section{Semantischer Umbau}

Vor dem knapp skizzierten Hintergrund lassen sich die Tendenzen westdeutscher Geschichtsschreibung unschwer einordnen. Dabei ist allerdings zunächst darauf hinzuweisen, daß Historiker in der intellektuellen Sinngebung nach dem Zweiten Weltkrieg keine führende Rolle spielten. Im Vordergrund der Schulddebatte stand die »Revisionsliteratur ${ }^{14}$ von Theologen, Philosophen, vereinzelt auch Soziologen und nur wenigen Historikern; für die Konstruktion abendländischer Tradition brauchte man diese nicht unbedingt als Experten, da sie mit ihren Spezialkenntnissen des Geschichtsverlaufs mitunter eher zur Irritation beitragen mochten. Aber natürlich ließen auch sie sich die Chance nicht entgehen, angesichts der historischen Aufladung der AbendlandBegrifflichkeit ihre Stimme autoritativ zu erheben. Im »Moratorium der Man-

12 Zit. nach Abendland: Die missionäre Monarchie, in: Der Spiegel, Nr. 33/1955, S. 12-14, hier S. 12; vgl. zur Lechfeld-Feier 1955 ausfiuhrlich Matthias PAPE, Lechfeldschlacht und NATO-Beitritt. Das Augsburger "Ulrichsjahr« 1955 als Ausdruck der christlichabendländischen Europaidee in der Ära Adenauer, in: Zeitschrift des Historischen Vereins für Schwaben 94 (2001), S. 269-308.

13 Axel SCHILDT, Mending Fences. The Federal Republic of Germany and the European East, in: Eduard MÜHLE (Hg.), Germany and the European East in the Twentieth Century, Oxford, New York 2003, S. 153-179.

14 Winfried SCHULZE, Deutsche Geschichtswissenschaft nach 1945, München 1993 (EA 1989), S. 46f. 
darine ${ }^{15}$ gab es trotz einer letztendlich recht milden Entnazifizierung viele Stimmen, die, wie etwa Hermann Aubin 1945, in düsterem Ton den »Untergang des Abendlandes« konstatierten ${ }^{16}$. Gleichzeitig fungierte das »christliche Abendland $/$ im Sinne Freyers als »Identitätskonstruktion ${ }^{17}$, die zu einer Integration und der Wiedergewinnung einer Sprecherrolle der Historiker verhelfen sollte. Flexible Strategien eines »semantischen Umbaus«, in denen sowohl wissenschaftsdisziplinäre wie politische Logiken beachtet wurden, waren entscheidend für das Gelingen dieses Ziels, wie der Literaturwissenschaftler Georg Bollenbeck betonte: Im »Zwischenbereich von fachlich-wissenschaftlicher und politischer Kommunikation dokumentieren die semantischen Umbauten den >Platzierungssinn (Pierre Bourdieu) des akademischen Personals ${ }^{18}$. Aus diesem Grund läßt sich das Thema der Abendland-Konjunktur in der Geschichtsschreibung auch nicht im engen Sinne als Wissenschaftsgeschichte, sondern nur im Zusammenhang von dieser mit einer weiteren intellectual history und der Entwicklung politischer Kultur verstehen.

Die Dominanz der Abendland-Begrifflichkeit kam den Historikern besonders entgegen, weil sie ihnen professionell geläufig war, so daß kaum Umformulierungsprobleme bestanden. Es war kein Zufall, daß in der prominenten Schrift über die "deutsche Katastrophe» von Friedrich Meinecke von der

15 Bernd WEISBROD, Dem wandelbaren Geist. Akademisches Ideal und wissenschaftliche Transformation in der Nachkriegszeit, in: DERS. (Hg.), Akademische Vergangenheitspolitik. Beiträge zur Wissenschaftskultur der Nachkriegszeit, Göttingen 2002, S. 11-35, hier S. 19f., 28; vgl. zu den universitären Rahmenbedingungen allgemein Axel SCHILDT, Im Kern gesund? Die deutschen Hochschulen 1945, in: Helmut KöNIG, Wolfgang KUHLMANN, Klaus SCHWABE (Hg.), Vertuschte Vergangenheit. Der Fall Schwerte und die NSVergangenheit der deutschen Hochschulen, München 1997, S. 223-240.

16 Zit. nach Eduard MÜHLE, Für Volk und deutschen Osten. Der Historiker Hermann Aubin und die deutsche Ostforschung, Düsseldorf 2005, S. 125; vgl. zum Kontext Peter SEGL (Hg.), Moderne und Mittelalter. Entdeckung und Rekonstruktion der mittelalterlichen Welt, Sigmaringen 1997; allgemeine Skizzen zu den neuen Bedingungsfaktoren für die Geschichtswissenschaft bieten Bernd FAULENBACH, Historistische Tradition und politische Neuorientierung. Zur Geschichtswissenschaft nach der »deutschen Katastrophe«, in: Walter H. PEHLE, Peter SILLEM (Hg.), Wissenschaft im geteilten Deutschland. Restauration oder Neubeginn nach 1945, Frankfurt a.M. 1992, S. 191-204; Otto Gerhard OEXLE, "Zusammenarbeit mit Baal«. Über die Mentalitäten deutscher Geisteswissenschaftler 1933 - und nach 1945, in: Historische Anthropologie 8 (2000), S. 1-27; Klaus GROSSE KRACHT, Die zankende Zunft. Historische Kontroversen in Deutschland nach 1945, Göttingen 2005, S. 23-46; Jan ECKEL, Hans Rothfels. Eine intellektuelle Biographie im 20. Jahrhundert, Göttingen 2005, S. 265ff., 336ff.

17 Heidrun KÄMPER, Der Schulddiskurs in der frühen Nachkriegszeit. Ein Beitrag zur Geschichte des sprachlichen Umbruchs nach 1945, Berlin, New York 2005, S. 415.

18 Georg BOLLENBECK, Das neue Interesse an der Wissenschaftshistoriographie und das Forschungsprojekt »Semantischer Umbau der Geisteswissenschaften «, in: DERS., Clemens KNOBLOCH (Hg.), Semantischer Umbau der Geisteswissenschaften nach 1933 und 1945, Heidelberg 2001, S. 9-40, hier S. 16, 20. 
»weltbürgerlichen Kulturgemeinschaft des christlichen Abendlandes« die Rede war, "wie sie tatsächlich bestanden hat und nach unseren heißesten Wünschen wieder aufblühen sollte ${ }^{19}$ - dies war der Rückgriff auf eine selbstverständliche begriffliche Größe des Historismus seit Leopold Ranke, der in der Einleitung seiner "Deutschen Geschichte im Zeitalter der Reformation « (1839) die "Gefahr des Abendlandes« durch die doppelte Bedrohung von islamischer und heidnischer Seite ausgemalt hatte.

Die Historiker hatten in der erwähnten politisch-propagandistischen Abendland-Konjunktur des Zweiten Weltkriegs einen festen Platz eingenommen. Die Rede Aubins zum 700. Jahrestag der Mongolenschlacht bei Liegnitz, die er zwei Monate vor dem Überfall auf die Sowjetunion hielt und in der er die Tapferkeit der deutschen Krieger beschwor, die seit Jahrhunderten das Abendland vor den "vernichtenden Einbrüchen asiatischer Völker « bewahrt hätten ${ }^{20}$, wies durchaus Anklänge an die zitierten späteren Äußerungen des ersten Bundesaußenministers auf. Karin Schönwälder hat in ihren Studien zur Geschichtswissenschaft im »Dritten Reich« auf den Wechsel der Zentralbegriffe »Volk - Mitteleuropa - Reich - Abendland ${ }^{21}$ aufmerksam gemacht. Nach Kriegsbeginn, als sich die Historiker im Rahmen der "Aktion Ritterbusch« in die Front der »Deutschen Geisteswissenschaft« einordneten und auf einer großen Konferenz in Nürnberg im Februar 1941 über »Das Reich und Europa» nachdachten - Teilnehmer u.a. Gerhard Ritter und Siegfried A. Kaehler ${ }^{22}$-, und erst recht nach der Kriegswende von Stalingrad wurde die Verteidigung des Abendlandes gegen den »Bolschewismus« auch zu ihrer zentralen Parole und blieb es nach dem Zweiten Weltkrieg ${ }^{23}$.

20 Zit. nach MÜHLE, Für Volk (wie Anm. 16), S. 119.

21 Karen SCHÖNWÄLDER, »Lehrmeisterin der Völker und der Jugend«. Historiker als politische Kommentatoren, 1933-1945, in: Peter SCHÖTTLER (Hg.), Geschichtsschreibung als Legitimationswissenschaft 1918-1945, Frankfurt a.M. 1997, S. 128-165, hier S. 152. Frank-Rutger HAUSMANN, "Deutsche Geisteswissenschaft« im Zweiten Weltkrieg. Die "Aktion Ritterbusch" (1940-1945), Dresden, München 1998, S. $181 \mathrm{ff}$.

23 Vgl. Karen SCHÖNWÄLDER, Historiker und Politik. Geschichtswissenschaft im Nationalsozialismus, Frankfurt a.M., New York 1992, S. 237ff.; vgl. zum Institutionengeflecht der historiographischen und interdisziplinären Ostforschung im "Dritten Reich« u.a. Michael BuRLEIGH, Germany Turns Eastwards. A Study of Ostforschung in the Third Reich, Cambridge 1988; Gabriele CAMPHAUSEN, Die wissenschaftliche historische Ostforschung im Dritten Reich, Frankfurt a.M. 1990; Ingo HAAR, Historiker im Nationalsozialismus. Deutsche Geschichtswissenschaft und der $»$ Volkstumskampf $«$ im Osten, Göttingen 2000 ( $\left.^{2} 2002\right)$; DERS., »Kämpfende Wissenschaft«. Entstehung und Niedergang der völkischen Geschichtswissenschaft im Wechsel der Systeme, in: Winfried ScHULZE, Otto Gerhard OEXLE (Hg.), Deutsche Historiker im Nationalsozialismus, Frankfurt a.M. 1999, S. 215-240; ideengeschichtliche Hinweise zu Kontinuitäten bereits in: Wolfgang WIPPERMANN, Der >deutsche Drang nach Ostenr. Ideologie und Wirklichkeit eines politischen Schlagwortes, Darmstadt 1981, S. $117 \mathrm{ff}$. 
Allerdings sollte ebenso wie für die gesamte politisch-kulturelle Entwicklung nach dem Zweiten Weltkrieg auch im Blick auf die Historiker und die Tendenzen der Geschichtswissenschaft die allgemeine Konjunktur der Abendland-Begrifflichkeit von einer spezifischen supranational-antiborussischen Strömung unterschieden werden.

\section{Nationalkonservative Adaption des Abendlandes}

Ein geschichtspolitisch zentraler Akteur unter den Historikern war Gerhard Ritter (1888-1967), der 1948 erster Vorsitzender des neu gegründeten Verbandes der Historiker Deutschlands (VHD) wurde ${ }^{24}$. Ihm ging es um eine elastische Apologie, die das »altpreußische Wesen« geradezu als Antipoden des "neudeutschen Nationalismus« konstruierte. In scharfer Kritik der »unglückseligen Theorie« vom »Volk ohne Raum« hatte er schon 1945 in einer Denkschrift für die Evangelische Kirche in Deutschland (EKD) den »überreizten Nationalismus « von "Grenzdeutschen ${ }^{25}$ als Ursache der »deutschen Katastrophe« benannt. In »Geschichte als Bildungsmacht« (1946) fragte er davon ausgehend, ob es nicht sinnlos sei, »daß ein einzelner Mensch diesen ungeheuren Einfluß der Barbarei über das Abendland herbeizuführen vermochte, den wir erlebt haben ${ }^{26}$. Ritter war die Abendland-Terminologie selbstverständlich vertraut, nicht zuletzt aus dem lockeren Widerstandskreis um Carl Goerdeler. Wenig originell war seine Hervorhebung des wmodernen Menschenmassentums" als "Nährboden für die Agitation moderner Volksführer und für die Errichtung stotalitärer/ Volksstaaten«, mit der Hitlers Erfolg als "keine Besonderheit der deutschen Entwicklung«, sondern als Kennzeichen im "Zeitalter des allgemeinen Kulturzerfalls, der Glaubenslosigkeit und des moralischen Nihilismus« beschrieben werden konnte ${ }^{27}$. Damit formulierte er

24 Die bewußte Konzentration von Ritter auf die Zeitgeschichte erklärt Christoph CORNELISSEN, Gerhard Ritter. Geschichtswissenschaft und Politik im 20. Jahrhundert, Düsseldorf 2001, S. 522ff.; vgl. auch SCHULZE, Deutsche Geschichtswissenschaft (wie Anm. 14), S. 64ff. CORNELISSEN, Gerhard Ritter (wie Anm. 24), S. 528.

${ }^{26}$ Gerhard RITTER, Geschichte als Bildungsmacht. Ein Beitrag zur historisch-politischen Neubesinnung, Stuttgart 1946, S. 13.

${ }^{27}$ Gerhard RITTER, Europa und die deutsche Frage. Betrachtungen über die geschichtliche Eigenart deutschen Staatsdenkens, München 1948, S. 194f., 199; die hier noch anzutreffende Anmerkung, dies sei »keine Entschuldigung « (ibid. S. 200), folgte dem nicht logisch und konnte später fallengelassen werden; vgl. zur Kritik der »Vermassung « im größeren Zusammenhang der aufeinander aufbauenden Kritik von Technik, Masse und Entfremdung Axel SCHILDT, Moderne Zeiten. Freizeit, Massenmedien und ,Zeitgeist in der Bundesrepublik der 50er Jahre, Hamburg 1995, S. 324ff. 
nur ein traditionsreiches Narrativ auch der Abendland-Ideologie, allerdings ohne Mittelalter-Verklärung und konfessionelle Schuldzuschreibungen. In diesem Zusammenhang ist auch die selbstkritische Passage seiner Rede auf dem ersten Nachkriegs-Historikertag in München 1949 zu lesen, daß die "Differenzierung des mittelalterlich-christlichen Abendlandes durch Herausbildung der modemen europäischen Nationalstaaten " noch das "Grundthema der Universalhistorie Rankes« gewesen sei, während seine Nachfolger »alle mehr oder weniger Nationalhistoriker « geworden $\operatorname{seien}^{28}$. Den Verlust »abendländischen Denkens im Bad des Historismus seit rund einem Jahrhundert" beklagte Paul Egon Hübinger in einem fast gleichzeitig erschienenen programmatischen Aufsatz der neuen Zeitschrift für Geschichtslehrer "Geschichte in Wissenschaft und Unterricht«. »Die Einordnung der deutschen Vergangenheit an falscher Stelle des abendländischen Geschichtsverlaufs«, die zur illusionären Annahme geführt habe, Preußen und Deutschland könnten »ernsthaft mit den europäischen Flügelmächten im Kampf um die Vorherrschaft rivalisieren«, müsse nun durch eine Besinnung auf die »Kräfte der europäischen Tradition « korrigiert werden ${ }^{29}$.

Gerade für nationalsozialistisch besonders belastete Historiker bot sich diese Besinnung als Eintrittsbillet in die sich neu formierende akademische Welt an, wie sich am Beispiel von Otto Brunners »alteuropäischer« Wende vom Völkischen zum Abendländischen anschaulich darstellen läßt ${ }^{30}$. Diese Wende, die er im Ausklang seiner Hamburger Rede über "Abendländisches Geschichtsdenken « 1954 mit einer bizarren Selbstkritik ausklingen ließ - im Anschluß an Theodor Litt formulierte er, »aber man muß wohl auch einmal einen

28 Gerhard RITTER, Gegenwärtige Lage und Zukunftsaufgaben der deutschen Geschichtswissenschaft (Eröffnungsvortrag des 20. Deutschen Historikertags in München am 12. September 1949), in: Historische Zeitschrift (HZ) 170 (1950), S. 1-22, hier S. 4; vgl. DERS., Deutsche Geschichtswissenschaft im 20. Jahrhundert, in: Geschichte in Wissenschaft und Unterricht (GWU) 1 (1950), S. 81-96, 129-237; DERS., Deutsche Geschichtswissenschaft heute, in: Zeitwende 2 (1953), S. 377-381.

29 Paul Egon HÜBINGER, Um ein neues deutsches Geschichtsbild, in: GWU 1 (1950), S. 385-401, hier S. 385, 392, 400.

${ }^{30}$ Vgl. Robert JÜTTE, Zwischen Ständestaat und Austrofaschismus. Der Beitrag Otto Brunners zur Geschichtsschreibung, in: Tel Aviver Jahrbuch für deutsche Geschichte 13 (1984), S. 237-262; korrigierend Reinhard BLÄNKNER, Von der "Staatsbildung« zur "Volkwerdung". Otto Brunners Perspektivenwechsel der Verfassungshistorie im Spannungsfeld zwischen völkischem und alteuropäischem Geschichtsdenken, in: Luise SCHORN-SCHÜTTE (Hg.), Alteuropa oder Frühe Moderne. Deutungsmuster für das 16. bis 18. Jahrhundert aus dem Krisenbewußtsein der Weimarer Republik in Theologie, Rechtsund Geschichtswissenschaft, Berlin 1999, S. 87-135; DERS., Nach der Volksgeschichte. Otto Brunners Konzept einer »europäischen Sozialgeschichte«, in: Manfred HETTLING (Hg.), Volksgeschichten im Europa der Zwischenkriegszeit, Göttingen 2003, S. 326-366; Thomas ETZEMÜLLER, Sozialgeschichte als politische Geschichte. Werner Conze und die Neuorientierung der westdeutschen Geschichtsschreibung nach 1945, München 2001, S. $72 \mathrm{ff} ., 86 \mathrm{ff}$. 
Irrweg zu Ende gehen, um ihn als solchen zu erkennen und den rechten Weg zu finden $\wedge^{31}-$, schuf übrigens eine ganz eigene Konstruktion des »Abendlandes«, das von Brunner nicht primär auf das Mittelalter bezogen wurde, sondern nun die »Zeitspanne von Homer bis Goethe« umschlo $3^{32}$. Diese kühne Konstruktion hatte zwar wenig mehr mit Geschichtswissenschaft zu tun, stellte aber ein um so attraktiveres bildungsbürgerliches Angebot dar.

Das Reden von der »europäischen« bzw. synonym »abendländischen« Tradition drückte die semantischen Umbau-Notwendigkeiten in idealer Weise aus. So konnte die seit Ende des Ersten Weltkriegs betriebene Westforschung - etwa in der "Bonner Schule" von Franz Steinbach (1895 1964) und Franz Petri (1903-1993) ${ }^{33}$ - vom expansionistischen 》Grenzkampf« auf »europäische Zusammenarbeit" gedreh $^{34}$ und insofern weitgehend problemlos in die Abendland-Ideologie eingepaßt werden. Kleinere Schwierigkeiten bereitete ınur die Berücksichtigung der Logik des Faches und der eigenen Biographie. Man kann den Umgang damit studieren, wenn man etwa Hermann Aubins Lob - von 1949 - für den »Nachweis germanischen Volkserbes in Wallonien und Nordfrankreich « durch Franz Petri (1937) einerseits und seine gleichzeitige Kritik an Otto Höflers Schlagwort vom "germanischen Kontinuitätsproblem « (ebenfalls 1937) andererseits nachliest ${ }^{35}$. Die Mega-Ausstellung »Werdendes Abendland an Rhein und Ruhr«, in Krupps Villa Hügel im Beisein von Bundespräsident Theodor Heuss, Bundeskanzler Konrad Adenauer, allen katholischen und vielen evangelischen Bischöfen sowie zahlreichen Ministern des Bundes und der Länder, im Mai 1956 eröffnet, symbolisiert das Gelingen semantischen Umbaus bei Fortbestehen »altbewährter Strukturen $\aleph^{36}$.

31 Otto BRUNNER, Abendländisches Geschichtsdenken. Rede gehalten anläßlich der Feier des 35. Jahrestages der Universität Hamburg am 19. Mai 1954, Hamburg 1954, S. 38.

32 BLÄNKNER, Von der "Staatsbildung« (wie Anm. 30), S. 117. Bei Brunner, der von der katholischen zur evangelischen Seite konvertiert war, fehlte sichtlich die ansonsten meist übliche christliche Note des Abendlandes.

33 Das Beispiel der "Bonner Schule« zeigt, daß der Begriff der »nationalkonservativen Adaption « (s.o.) nicht auf protestantische Historiker verengt werden darf, wurde Kontinuität doch in diesem Fall durch »Persilscheine« katholischer Bischöfe und im Rahmen der Görres-Gesellschaft gestiftet.

34 Vgl. Peter SCHÖTTLER, Von der rheinischen Landesgeschichte zur nazistischen Volksgeschichte oder Die nunhörbare Stimme des Blutes«, in: SCHULZE, OEXLE ( $\mathrm{Hg}$.), Deutsche Historiker (wie Anm. 23), S. 89-113, hier S. 95; vgl. DERS., Die historische "Westforschung " zwischen "Abwehrkampf" und territorialer Offensive, in: DERS., Geschichtsschreibung als Legitimationswissenschaft (wie Anm. 21), S. 204-261.

35 Hermann AUBIN, Vom Altertum zum Mittelalter. Absterben, Fortleben und Erneuerung, München 1949, S. 47, 68.

36 Hans DERKS, Deutsche Westforschung. Ideologie und Praxis im 20. Jahrhundert, Leipzig 2001, S. 211. 
Wie bereits angedeutet, waren die Probleme semantischen Umbaus hinsichtlich der $»$ Ostforschung ${ }^{37}$ weit geringer, konnte hier doch auf einer im Krieg bereits entwickelten »antibolschewistischen Langzeitstrategie ${ }^{38}$ aufgebaut werden. Als Ergebnis einer Unterredung am Rande des Historikertags 1949 zur Institutionalisierung einer interdisziplinären Ostforschung - Teilnehmer u.a. Hans Rothfels, Theodor Schieder, Werner Conze, Walter Hubatsch und Bundesminister Theodor Oberländer - hielt Aubin fest: "Wir brauchen uns nicht umzustellen. Natürlich geht es weiterhin, wie stets, um die reine Wahrheit ${ }^{39}$. Mit dieser Selbstgewißheit wurde an den Universitäten eine "pathetische Abendland-Apotheose ${ }^{40}{ }^{0}$ zelebriert. Der nun in Hamburg lehrende Aubin, der 1950 eine vom Abendland besonders geprägte Geschichtsepoche nach "schmerzvoll-gewaltigen Wehen ${ }^{41}$ heraufziehen sah, war die treibende Kraft bei der Gründung des Herder-Forschungsrats, als dessen erstes Projekt das Grundlagenwerk »Grundriß des abendländischen Ostraums« geplant wurde ${ }^{42}$.

Von größtem Wiedererkennungswert war die Abendland-Ideologie für die Historiker, die an jenen »Grenzland«-Universitäten gelehrt hatten, die sich als Vorposten des Abendlandes verstanden hatten, vor allem Breslau und Königsberg. Hermann Aubin, Werner Conze, Theodor Schieder und vielen anderen war das Denken in den Kategorien und die Metaphorik von »Europa gegen Asien « bestens vertraut ${ }^{43}$. Daß gerade deren Expertise für die regierungsoffiziöse $»$ Dokumentation der Vertreibung der Deutschen aus Ost-Mittel-

37 Vgl. Eduard MÜHLE, `Ostforschung «. Beobachtungen zu Aufstieg und Niedergang eines geschichtswissenschaftlichen Paradigmas, in: Zeitschrift für Ostmitteleuropa-Forschung 46 (1997), S. 317-349; Wlodzimierz BORODZIEJ, ’Ostforschung aus der Sicht der polnischen Geschichtsschreibung, in: Ibid. S. 405-426; vgl. Kai Arne LINNEMANN, Das Erbe der Ostforschung. Zur Rolle Göttingens in der Geschichtswissenschaft der Nachkriegszeit, Marburg 2002.

38 Hans-Erich VOLKMANN, Historiker aus Leidenschaft. Hermann Aubin als Volksgeschichts-, Kulturboden- und Ostforscher, in: Zeitschrift für Geschichtswissenschaft (ZfG) 49 (2001) S. 32-49, hier S. 40.

39 Zit. nach ibid. S. 44.

${ }^{40}$ Christoph KLESSMANN, Osteuropaforschung und Lebensraumpolitik im Dritten Reich, in: Peter LuNDGREEN (Hg.), Wissenschaft im Dritten Reich, Frankfurt a.M. 1985, S. 350 383, hier S. 370.

41 Hermann AUBIN, Zwischen Altertum und Neuzeit. Einheit und Vielfalt im Aufbau des mittelalterlichen Abendlandes, in: Walter HUBATSCH (Hg.), Schicksalswege deutscher Vergangenheit. Festschrift für S. A. Kaehler zum 65. Geburtstag, Düsseldorf 1950, S. 15 42, hier S. 15; im Wintersemester 1950/51 hatte er erstmals wieder eine Vorlesung zum »abendländischen Ostraum« gehalten; vgl. MÜHLE, Für Volk (wie Anm. 16), S. 138; vgl. Werner CoNzE ( $\mathrm{Hg}$.), Deutschland und Europa. Historische Studien zur Völker- und Staatenordnung des Abendlandes. Festschrift für Hans Rothfels, Düsseldorf 1951.

42 Vgl. MüHLE, Für Volk (wie Anm. 16), S. 417ff.

${ }^{43} \mathrm{Vgl}$. die wichtigen Arbeiten von ETZEMÜLLER, Sozialgeschichte als politische Geschichte (wie Anm. 30), S. 22, 25, 36, 217, 281; ECKEL, Hans Rothfels (wie Anm. 16), S. 312ff. 
europa" gesucht wurde, ergab sich aus der inhaltlichen Kontinuität der Ostforschung ebenso wie aus der Weiterexistenz der Netzwerke von Ministerialen und beteiligten Ordinarien, etwa der Verbindungen von Schieder zu Oberländer. Allerdings zeigten sich einige Widersprüche zwischen politischer und fachwissenschaftlicher Logik, etwa Querelen zwischen der von Schieder organisierten Forschergruppe und Ansprüchen der Vertriebenen-Funktionäre ${ }^{44}$.

\section{Die supranationale Abendland-Strömung}

Unter den Abendland-Ideologen, die nach dem Krieg ihre Stimme erhoben, gab es einige Historiker, die nicht zum nationalkonservativ geprägten inner circle des Faches gehört hatten und nun - angesichts der veränderten Rahmenbedingungen - eine Chance sahen, die Meinungsführerschaft $\mathrm{zu}$ erobern. Dazu zählte der Soziologe und Historiker Alfred von Martin (1882-1979), ein dezidierter Kritiker Gerhard Ritters ${ }^{45}$, der sich mit zeittypischen Beiträgen zur Schulddebatte in Broschürenform einmischte ${ }^{46}$. Für Martin war Deutschland im christlichen Mittelalter als "Verwalter des heiligen, des vom sacerdotium geweihten Imperiums, des abendländischen, der Ideen nach universalen Kaisertums wesentlicher Träger des hohen Gedankens von der politischen Versichtbarung und Verwirklichung der religiös sittlichen Weltordnung « gewesen. Das Deutschtum sei durch seine Verchristlichung "zugleich humanisiert, europäisiert« worden. Doch unter dieser Hülle sei das »potentielle - und stets mit Aktualisierung drohende - Antieuropäertum des Deutschen eine Gegebenheit« geblieben. Die »antihumanistische Wirkung, die von Luther ausging« und im Preußischen ihren Ausdruck gefunden habe, wurde von Martin

Dokumentation der Vertreibung der Deutschen aus Ost-Mitteleuropa. In Verbindung mit Adolf Diestelkamp, Rudolf LAUN, Peter Rassow, Hans RothFELS (und ab Bd. 3 mit Werner CONZE) bearbeitet von Theodor SCHIEDER, hg. v. Bundesministerium für Vertriebene, Bonn 1953-1961 (unveränderter Nachdruck: München 1984); vgl. Matthias BEER, Im Spannungsfeld von Politik und Zeitgeschichte. Das Großforschungsprojekt "Dokumentation der Vertreibung der Deutschen aus Ost-Mitteleuropa«, in: Vierteljahrshefte für Zeitgeschichte (VfZ) 46 (1998), S. 345-389, hier S. 362, 368, 374, 376; DERS., Der "Neuanfang" der Zeitgeschichte nach 1945. Zum Verhältnis von nationalsozialistischer Umsiedlungs- und Vernichtungspolitik und der Vertreibung der Deutschen aus Ostmitteleuropa, in: SchulzE, OEXLE (Hg.), Deutsche Historiker (wie Anm. 23), S. 274 301.

45 Vgl. CORNELISSEN, Gerhard Ritter (wie Anm. 24), S. 531.

46 Alfred VON MARTIN, Geistige Wegbereiter des deutschen Zusammenbruchs (Hegel, Nietzsche, Spengler), Recklinghausen 1948; die folgenden Zitate S. 6, 7, 8, 24; vgl. auch DERS., Geschichte vom Standpunkt der Humanität, Ulm 1947; DERS., Entpreußung des deutschen Geschichtsunterrichts, in: Stimmen der Zeit 142 (1948), S. 61-67. 
zusammengefaßt: "Der Deutsche hörte (in der Nachfolge Hegels; A.S.) auf, bürgerlich, und begann, militaristisch zu denken - exemplarisch zu beobachten an Treitschke im Jahr des deutschen Unheils 1866 «.

Ein weiterer profilierter Vertreter abendländischer Gedanken war Franz Borkenau (1900-1957), einflußreicher Totalitarismus-Theoretiker, dessen intellektuelle Anfänge in der kommunistischen Bewegung und in der kritischen Theorie der »Frankfurter Schule« wurzelten, der aber in der Zeit des US-Exils bereits eine merkwürdige Konversion vollzogen hatte, die ihn als Protagonist des modernen Westens wie abendländischer Traditionen gleichermaßen erscheinen ließ; er publizierte ebenso im liberalen »Monat" wie im "Neuen Abendland ${ }^{47}$. Ein konzeptioneller Beitrag des Remigranten - er erhielt 1947 nach hinhaltendem Widerstand der Fakultät eine außerplanmäßige Professur in Marburg, wandte sich aber bereits zwei Jahre später dem Journalismus zu - in der $»$ Schulddebatte $\ll$ lautete: $» D i e$ Ich-Form der Rede und der abendländische Individualismus ${ }^{48}$. Die Freiheit des Abendlandes bzw. - synonym - des Westens sei eben "nicht die Freiheit eines die Gesellschaft in seinem Innersten verachtenden, zu den höchsten Höhen mystischer Selbstgestaltung aufsteigenden Individuums. Dieser Individualismus ist im Westen verpönt. Das Individuum hat seine Freiheit dauernd auf die Gesellschaft zu beziehen, in der es lebt ${ }^{49}$. Und eben deshalb sei Luthers »innere Freiheit des Menschen in seinem unmittelbaren Verhältnis zu Gott« für den Westen unbrauchbar, weil, "paradoxerweise, viel zu individualistisch $\aleph^{50}$. Das »Luthertum« sei »ein vom Osten her bedingter Protest gegen das Abendland « und habe gezeigt, daß "zwar Westdeutschland ein echter und eindeutiger Teil des Abendlandes war", nicht aber Ostdeutschland ${ }^{51}$. Aus dieser Gespaltenheit ergab sich für Borkenau, daß die nationalgeschichtliche Entwicklung habe ins Unglück führen müssen, während nun eine konsequente Politik des abendländischen Teils Deutschlands an der Seite der westlichen Mächte betrieben werden müsse.

Prominenter als Borkenau war ein weiterer Marburger, der im »Dritten Reich« als »Jude« stigmatisierte, aber zur katholischen Kirche konvertierte Ludwig Dehio (1888-1963), der im ersten Nachkriegsjahrzehnt das dortige Staatsarchiv und die angegliederte Archivschule leitete und von 1949 bis 1956

47

Vgl. Hinweise in Michael HochgESCHWENDER, Freiheit in der Offensive? Der Kongreß für kulturelle Freiheit und die Deutschen, München 1998, S. 100, 147; SCHILDT, Zwischen Abendland und Amerika (wie Anm. 2), S. 14f., 30; die Ambivalenzen im Werk von Borkenau werden in der Historiographie der politischen Remigration bisher weitgehend ignoriert; vgl. als Ausnahme Mario KESSLER, Zwischen Kommunismus und Antikommunismus: Franz Borkenau (1900-1957), in: DERS. (Hg.), Deutsche Historiker im Exil (1933-1945). Ausgewählte Studien, Berlin 2005, S. 169-196.

48 Franz BORKENAU, Drei Abhandlungen zur deutschen Geschichte, Frankfurt a.M. 1946.

Ibid. S. 72.

so lbid. S. 73.

51 Ibid. S. 107. 
- auf Vorschlag von Friedrich Meinecke - Herausgeber der Historischen Zeitschrift wurde ${ }^{52}$. Seine Konstruktion einer im Nationalsozialismus kumulierenden Auflösung des Abendlandes, die er in seinem Nachkriegswerk »Gleichgewicht oder Hegemonie« (1949) vornahm, zeigt exemplarisch die theoretische Hilflosigkeit der »abendländischen« Erklärung der »deutschen Katastrophe ${ }^{53}$. Nach dem Ersten Weltkrieg habe das »Unberechenbare asiatischer Färbung«, die bolschewistische Revolution, die 》Gefährdung der nationalen Existenz von innen heraus [...] die Abwehrkräfte des deutschen Volkskörpers « geweckt. »Wie ein schwer verwundeter Löwe richtete sich der Preußengeist aus seiner Betäubung auf«. Eben diesen Abwehrimpuls habe Hitler demagogisch mißbraucht. Anders als das betrogene Volk dachte, handelte es sich nicht um die "friedliche Heilung chronischen Siechtums durch einen Zaubertrunk", sondern um die "vorbereitende Narkose zu einer Operation mit dem Messer«. Unter Hitler seien zu der merneuerten altpreußischen militaristisch-bürokratischen Tradition « dann die "modernsten revolutionären Methoden« hinzugetreten. »Wohlbekannte Züge unserer neuen Geschichte « hätten sich in »fieberhafter Übersteigerung « wiedergefunden; mit dem Ende dieses Krieges aber sei der deutsche Patient geheilt worden. Diese nur "verhaltene Abrechnung mit der rankeanischen Machtgeschichte ${ }^{54}$ hatte geringen analytischen Tiefgang und war jedenfalls nicht geeignet, als Gegenposition gegen Ritters Position zu bestehen. Nur in einem Punkt war Dehio sehr radikal, dies aber im Mainstream der politischen Kultur der AdenauerÄra. In seiner Schrift »Deutschland und die Weltpolitik im 20. Jahrhundert ${ }^{55}$ hielt er fest: »Auch unsere Wiedervereinigung in Freiheit, die Bewahrung abendländischen Menschentums in Deutschland, setzt feste Bindung an die Angelsachsen voraus und jede Lockerung gefährdet sie, wenn nicht sofort, dann auf die Länge«. Eine Wiedervereinigung sei allein »im Zuge erhoffter Zurückdrängung des Bolschewismus auf breiter Front, als Teilergebnis allgemeiner und solidarischer Befreiungsaktion «, anzustreben, vor der Einheit stehe allemal die (abendländische) Freiheit. Mit dieser Positionsbestimmung ordnete sich Dehio am radikalen Rand der offiziösen Parole von der Wiedervereinigung in "Einheit und Freiheit« ein, aber dies hatte mit einer geschichtswissenschaftlichen Betrachtung wenig mehr zu tun.

Als Historiker ungleich bedeutender war sicherlich Franz Schnabel (18871966), ein Kenner vor allem der Geschichte des 19. Jahrhunderts, auch er

52 Vgl. Volker BERGHAHN, Ludwig Dehio, in: Hans Ulrich WEHLER ( $\mathrm{Hg}$.), Deutsche Historiker, Bd. 4, Göttingen 1972, S. 97-116; SCHULZE, Deutsche Geschichtswissenschaft (wie Anm. 14), S. $87 \mathrm{ff}$.

53 Ludwig DEHIO, Gleichgewicht oder Hegemonie. Betrachtungen über ein Grundproblem der neueren Staatengeschichte, Krefeld 1949; die folgenden Zitate S. 344-356.

54 SCHULZE, Deutsche Geschichtswissenschaft (wie Anm. 14), S. 108.

55 Ludwig DEHIO, Deutschland und die Weltpolitik im 20. Jahrhundert, München 1955; die folgenden Zitate dort S. $147 \mathrm{f}$. 
nicht belastet durch nationalsozialistisches Engagement ${ }^{56}$. Im Gegenteil, er hatte 1936 Berufsverbot erhalten. Nach dem Krieg lehrte er an der Universität München und war von 1951 bis 1959 Präsident der Historischen Kommission bei der Bayerischen Akademie der Wissenschaften. Allerdings war Schnabel, der »einzig denkbare Gegenpol zu Gerhard Ritter auf katholischer Seite « ${ }^{57}$, offensichtlich nicht bereit, seine durchaus vehement vertretene Kritik an der kleindeutschen Lösung - für ihn der entscheidende Irrweg deutscher Geschichte $^{58}$ - über das Fachliche hinaus zu einem geschichtspolitischen Engagement auszuweiten. Er entzog sich dem Werben der Zeitschrift »Neues Abendland «, die ihn gern gewonnen hätte, und insgesamt machte er aus seiner Skepsis gegenüber der Zeitgeschichte, auf die sich Ritter programmatisch konzentrierte, kein $\operatorname{Hehl}^{59}$.

Der ausgeprägte Individualismus auf Seiten der erwähnten supranationalabendländischen Historiker verhinderte zunächst, daß sich ein organisatorisch starker Zusammenschluß auf dieser Seite bildete. Ein "Arbeitskreis christlicher Historiker « (1947-1955), initiiert von dem im Fach eher randständigen und früh verstorbenen Wilhelm Wühr (1905-1950) von der PhilosophischTheologischen Hochschule Freising ${ }^{60}$, entwickelte nur geringe Wirksamkeit ${ }^{61}$. Eines der prominentesten Mitglieder war der Münsteraner Althistoriker HansErich Stier (1902-1979), der in seiner programmatischen Schrift über die "geistigen Grundlagen der abendländischen Kultur" (1947) zum einen von vornherein Amerika in das Abendland einbezog und zum anderen, da das Christentum mit keiner besonderen Verfassungsform verwachsen sei, eine »christliche Demokratie« propagierte, in der allerdings eine sehr konservativ geprägte "Volksbildung in echt christlichem Geiste gehalten sein« müsse ${ }^{62}$. Solche Gedanken wurden auch auf den von der französischen Besatzungsmacht geförderten internationalen Historikertreffen in Speyer von 1948 bis 1950 verbreitet $^{63}$, die einen Vorlauf zur Gründung des Instituts für Europäische Geschichte in Mainz bildeten.

56 Thomas HerTfElder, Franz Schnabel und die deutsche Geschichtswissenschaft. Geschichtsschreibung zwischen Historismus und Kulturkritik (1910-1945), Göttingen 1998.

57 SCHULZE, Deutsche Geschichtswissenschaft (wie Anm. 14), S. 212.

$58 \mathrm{Vgl}$. für das katholische Publikum Franz SCHNABEL, Das Problem Bismarck, in: Hochland $42(1949 / 50)$, S. 1-27.

59 Vgl. Wolfgang BENZ, Wissenschaft oder Alibi? Die Etablierung der Zeitgeschichte, in: PEHLE, SILLEM (Hg), Wissenschaft im geteilten Deutschland (wie Anm. 16), S. 11-25, hier $\mathrm{S} .11,16$.

${ }^{60}$ Vgl. die Präsentation seiner Forschungsinteressen: Wilhelm WÜHR, Monumenta Germaniae Historica in München, in: Neues Abendland (NA) 5 (1950), S. 100-103.

61 SCHULZE, Deutsche Geschichtswissenschaft (wie Anm. 14), S. $266 \mathrm{ff}$.

62 Hans-Erich STIER, Die geistigen Grundlagen der abendländischen Kultur, Gütersloh 1947, S. 81; die nachfolgenden Passagen zur Kultur atmen den Geist katholischer Kritik der Moderne.

63 Vgl. dazu den Beitrag von Corine DEFRANCE in diesem Band. 
Am äußersten rechten Rand der christlichen Demokratie und partiell rechts von ihr stand wie erwähnt die Gruppierung um die Zeitschrift »Neues Abendland « - kein Organ für Historiker, sondern ein Ort auch für diese, bisweilen einen Artikel zu verfassen, wenn sie sich dieser Strömung zugehörig fühlten. Die geschichtspolitische Linie hingegen wurde von Journalisten vorgegeben. Im Editorial der ersten Nummer schrieb der katholische Herausgeber Johann Wilhelm Naumann, es gelte, »der seit Treitschke, Droysen und Sybel verpreußten deutschen Geschichtsauffassung entgegenzutreten [...] Unsere Aufgabe soll es sein, den Ungeist eines preußischen Hochmuts, der Geschichtsfälschung und des vermassenden Militarismus zu bekämpfen [...] im Dienst der Erneuerung Deutschlands aus christlich-universalistischem Geist, also im Sinne echter abendländischer Geisteshaltung «; der Geschichtsprozeß hatte im Verständnis Naumanns dazu geführt, daß infolge der Zerstörung des abendländischen Universalismus durch die "Sucht der ratio, Dinge zu erklären, die nur glaubensmäßig zu sehen und zu finden sind [...], an die Stelle der Staatengemeinschaft des Heiligen Römischen Reiches [der] moderne Nationalstaat mit seiner letzten dämonischen Konsequenz, dem Nationalsozialismus «, getreten war; Deutschland müsse nun »durch die Sühne seiner Schuld zur Mater occidentalis zurückfinden ${ }^{64}$. Artikel gegen Gerhard Ritter, der zu viel von Westeuropa und zu wenig vom Abendland spreche, schrieben keine prominenten Professoren, sondern häufig etwa der Student der Geschichtswissenschaft Franz Herre (geb. 1926) ${ }^{65}$, der später journalistisch Karriere machte; zu den gern historisierenden Autoren gehörten im ersten Jahrgang der Zeitschrift u.a. der von der Sozialdemokratie zur Henlein-Partei und später zur CSU konvertierte sudetendeutsche Publizist und spätere Chefredakteur Emil Franzel sowie der Jurist Ernst von Hippel, dessen antibolschewistische Traktate aus der NS-Zeit von ihm mit geringfügigen Veränderungen seit Ende der 1940er Jahre erneut vermarktet wurden.

In den Vordergrund der Bewegung schob sich bald der CSU-Politiker Gerhard Kroll, ein aus Breslau stammender Jurist und Volkswirt ${ }^{66}$. Er wurde der führende Vertreter einer abendländischen Geschichtsrevision und fungierte von 1949 bis 1951 als Geschäftsführer des Instituts zur Erforschung der nationalsozialistischen Zeit in München, aus dem dann das Institut für Zeitgeschichte entstand. In dieser Eigenschaft geriet er in die vorderste Linie des Kampfes gegen die preußisch-nationalen Historiker, und als er 1950 den Posten des Generalsekretärs in dem neuen Institut anstrebte, traf er auf deren er-

${ }^{64}$ Johann Withelm NAUMANN, Neues Abendland, in: NA 1 (1946/47) 1, S. 1 3; vgl. auch DERS., Hegel und der preußische Geist, in: NA 1 (1946/47) 5, S. 29-30.

65 Vgl. Franz HERRE, Selbstbesinnung der abendländischen Geschichtswissenschaft, in: NA 4 (1949), S. 305-307.

${ }^{66}$ Vgl. zur Biographie von Kroll SCHILDT, Zwischen Abendland und Amerika (wie Anm. 2), S. 45f.; CONZE, Das Europa der Deutschen (wie Anm. 2), S. 73, 129 f. 
bitterten Widerstand. Gerhard Ritter sah ihn als »Intimfeind « an und verhinderte mit der Drohung, andernfalls aus dem Beirat auszutreten, Krolls Bestallung. Dessen Aktivitäten als Führer der Propagandavereinigung $» A b e n d-$ ländische Aktion« und Verfasser ihres Manifests, das einen fanatischen Antibolschewismus mit dem Ideal eines christlichen Ständestaats vereinbarte, sind in Umrissen bekannt. Interessant ist, daß sich als namhafter Historiker der Münchner Südosteuropa-Spezialist Georg Stadtmüller (1909-1985), Gründer der Zeitschrift "Saeculum«, der bei Aubin in Breslau Assistent gewesen und dort habilitiert worden war, zur "Abendländischen Aktion« bekannte und sowohl auf der Gründungsversammlung am 25. August $1951 \mathrm{im}$ Münchner Ärztehaus ${ }^{67}$ als auch auf der ersten öffentlichen Kundgebung im großen Saal des neuen Münchner Kolpinghauses am 4. März 1952 eine Rede hielt. Dabei verglich er das neue staatliche Gebäude mit einem »Behelfsheim«, das »nicht den Anspruch erheben kann, Abbild einer endgültigen Ordnung zu sein ${ }^{68}$.

Die Hauptkritik der »Abendländischen Aktion« galt der »formalen Demokratie«, die nicht ausreiche, dem weltanschaulich gepanzerten Bolschewismus zu widerstehen. Im »Neuen Abendland « stellte ein junger Mitarbeiter, Hermann Graml, die Frage, warum sich die an der Ostfront in Gefangenschaft geratenen Offiziere der Wehrmacht, die sich für das "Nationalkomitee Freies Deutschland« (NKFD) rekrutieren ließen, »eine geschlossene Gruppe von intelligenten, gebildeten Menschen aller Berufe, aller Gesellschaftsschichten Deutschlands und damit des Westens, beim ersten ernsthaften Zusammenstoß mit dem Bolschewismus versagt « hätten. Verantwortlich dafür machte er die "geistige Heimatlosigkeit«, und die Folgerung lautete, daß »die politischen Parolen des Westens nicht mehr befähigt« seien, »den Abwehrkampf gegen den Osten « zu tragen. Der "pseudoreligiöse Charakter des Gegners« könne "nur durch Religion überwunden werden«: »In der Herzkammer unserer Willensbildung muß der säkularisierte Begriff des Westens durch das Zukunftsbild eines erneuerten Abendlandes ersetzt werden ${ }^{69}$.

67 Abendländische Aktion, in: NA 6 (1951), S. 508-512; Georg STADTMÜLLER, Geschichtsbild und Geschichtsunterricht, in: Saeculum 5 (1951), S. 1-9; vgl. zu Stadtmüller CONZE, Das Europa der Deutschen (wie Anm. 2), S. 56, 85ff.; MüHLE, Für Volk (wie Anm. 16), S. 258; DIRSCH, Individualisierung und Traditionsbewahrung (wie Anm. 7), S. 110; das Beispiel Stadtmüller zeigt, daß es verfehlt ist, von einer "rein evangelischen " Aubin-Schule zu sprechen; Wolfgang WEBER, Priester der Clio. Historischsozialwissenschaftliche Studien zu Herkunft und Karriere deutscher Historiker und zur Geschichte der Geschichtswissenschaft 1800-1970, Frankfurt a.M. 1984, S. 246.

68 Zur ersten Kundgebung der Abendländischen Aktion am 4. März 1952 in München, in: NA 7 (1952), S. 242-245; vgl. auch Georg STADTMÜLLER, Geschichtsbild und Geschichtsunterricht, in: Saeculum 2 (1951), S. 1-9.

69 Hermann GRAML, Das Nationalkomitee "Freies Deutschland«, in: NA 7 (1952), S. 676680 , hier S. $679 f$. 
Diesem Bildungsauftrag dienten die erwähnten Zusammenkünfte der "Abendländischen Akademie« seit 1952, an denen sich auch namhafte Historiker beteiligten. Auf der ersten Jahrestagung unter dem Thema "Werte und Formen im Abendland« im August 1952 sprach Alois Dempf (München) über "Die Gegenwartskrise der abendländischen Kultur« und wandte sich dabei strikt gegen die Tendenz, die USA aus dem »Abendland« auszuschließen ${ }^{70}$; auf der zweiten Jahrestagung in Eichstätt 1953 referierte Karl Buchheim vom Institut für Zeitgeschichte zum Komplex der "Freiheit in der Heilsgeschichte ${ }^{71}$. Auf etlichen Wochenendtagungen und Vortragsabenden, die von der "Abendländischen Akademie» 1953 organisiert wurden, sprachen Historiker, darunter Franz Borkenau, Karl Buchheim, Alois Dempf und Georg Stadtmüller, die ein breites Themenspektrum traktierten ${ }^{72}$.

Höhepunkt der Aktivitäten war die dritte Jahrestagung der "Abendländischen Akademie« in Eichstätt Ende Juli/Anfang August 1954, die unter das Thema "Staat, Volk, übernationale Ordnung" gestellt worden $\mathrm{war}^{73}$. Die durchaus wahrgenommene Abwendung der Sozialdemokratie von marxistischem Gedankengut, so die dort vorgetragene Pointe Georg Stadtmüllers, mache alle Ansätze eines christlich-marxistischen Dialogs überflüssig ${ }^{74}$. Auch die liberale Partei im Regierungslager wurde hart attackiert; Franz Herre verbreitete sich über die "Leichenblässe des deutschen Liberalismus« mit seinen »nationalistischen Atavismen ${ }^{75}$.

\section{Begrenzte Konflikte}

Die geschichtspolitische Linie des »Neuen Abendlandes« war insofern interessant, als Anfang der 1950er Jahre zum einen die Polemik gegen abweichende katholische Historiker verstärkt wurde; so machte sich Franz Herre die heftigen Angriffe von Franz Schnabel und Alois Dempf gegen Friedrich Heer (1951) wegen dessen Versuch einer positiven Sicht auf die Aufklärung zu eigen - einige Jahre später erfolgte ein weiterer Frontalangriff von Gerhard

Alois DEMPF, Die Gegenwartskrise der abendländischen Kultur, in: Werte und Formen im Abendland. Jahrestagung der Abendländischen Akademie vom 6.-10.8.1952 in Eichstätt, hekt. Typoskript (o.O./o.J.), S. 1 .

7 Der Mensch und die Freiheit. Vorträge und Gespräche der (2.) Jahrestagung der Abendländischen Akademie 1953, München o.J. (1953).

72 Abendländische Akademie 1953, in: Diözesan-Archiv Eichstätt, o.Nr.

73 Staat, Volk, übernationale Ordnung. Vorträge und Gespräche der 3. Jahrestagung der Abendländischen Akademie 1954, München o.J.

74 Georg STADTMÜLlER, Abschied von Marx, in: NA 9 (1954), S. 257-258.

75 Franz HERRE, Liberalismus ohne Zukunft, in: NA 10 (1955), S. 227-228. 
Kroll gegen die Abwertung des Mittelalters durch den »katholischen Aufklärer« Heer ${ }^{76}$.

Der Verbreiterung des konservativen Lagers diente auf der anderen Seite die Mäßigung des antipreußischen Affekts, der das Gespräch mit protestantisch-konservativ gesinnten Kreisen behinderte. In einem programmatischen Aufsatz in »Neues Abendland" vereinnahmte Emil Franzel Bismarck als Föderalisten, der in seiner positiven historischen Bedeutung zu würdigen sei $^{77}$. Auf der Gründungsversammlung der »Abendländischen Aktion « 1951 wurde das Geschehen am 20. Juli 1944 als Beleg gegen die »billige Verdammung preußischen Wesens « angeführt ${ }^{78}$. In einem anderen Zusammenhang hatte Emil Franzel sogar die Männer des 20. Juli, die »letzte echte Elite, die wir besaßen«, als Kronzeugen für die Notwendigkeit abendländischer Elitebildung gewürdigt ${ }^{79}$. Allerdings ließ sich der positive Preußen-Bezug nicht gänzlich durchsetzen. Artikel, in denen das preußische Prinzip schlicht als "antikonservativ ${ }^{80}$ abgelehnt wurde, fanden sich auch künftig in »Neues Abendland«, und auch der Kampf gegen Gerhard Ritter, Hans-Joachim Schoeps und andere borussische Historiker wurde weiterhin mit harten Bandagen geführt ${ }^{81}$. Zur Preußen-Frage war die Diskussion, wenn schon nicht gewollt, so doch zumindest zugelassen, und neben der Ablehnung Preußens fand sich auch die gemäßigte Verteidigung - allerdings nur seines historischen Ranges, nicht etwa einer eventuellen Vorbildfunktion für die Gegenwart ${ }^{82}$.

Um 1950 waren wichtige Positionskämpfe bereits ausgefochten worden. Den Vorsitz des Historikerverbandes hatte - gegen manche Widerstände ${ }^{83}$ Gerhard Ritter erhalten, die Betrauung Ludwig Dehios mit der Herausgabe der "Historischen Zeitschrift" mag als gewisse Kompensation gewertet werden. Die beiden Strömungen schufen sich zur gleichen Zeit ihre institutionellen Zentren. Seit 1949 erschien das »Historische Jahrbuch« der 1946 wieder ge-

DERS., Der Christ vor der Geschichte. Zu den Salzburger Hochschulwochen 1951, in: NA 6 (1951), S. 500-504; Gerhard KROLL, Heiliges oder unheiliges Reich? Bemerkungen zu Friedrich Heers abendländischer Geschichtsdeutung, in: NA 11 (1956), S. 135-152.

77

78 Emil FRANZEL, Das Bismarckbild in unserer Zeit, in: NA 5 (1950), S. 233-230.

Abendländische Aktion (wie Anm. 67), S. 510.

${ }^{79}$ Franz MURNER (= Emil FRANZEL), Von Lassalle zu Schumacher, in: NA 5 (1950), S. 265-271, hier S. 266.

${ }^{80}$ Bernhard HÜLSMANN, Schicksal des Konservatismus im deutschen Raum, in: NA 6 (1951), S. 401-410, hier S. 405, 407f.

81 Franz HERRE, Preußens neue Ehre, in: NA 7 (1952), S. 607-614.

82 Hans ASMUSSEN, Noch einmal Preußen, in: NA 7 (1952), S. 735-738; lediglich einmal kam in einem (deutlich als Gastbeitrag gekennzeichneten) Artikel ein konservativer PreuBen-Apologet zu Wort: Hans Joachim SCHOEPS, Das Reich und die Wiederkehr PreuBens, in: NA 11 (1956), S. 255-258.

$83 \mathrm{Vgl}$. Hermann HEIMPEL, Aspekte. Alte und neue Texte, hg. von Sabine KRÜGER, Göttingen 1995, S. 265ff.; SCHULZE, Deutsche Geschichtswissenschaft (wie Anm. 14), S. 159ff. 
gründeten Görres-Gesellschaft ${ }^{84}$. In Hamburg wurde auf Anregung nationalsozialistisch belasteter Hochschullehrer, sogenannter »amtsverdrängter« Professoren, 1950 die Ranke-Gesellschaft ins Leben gerufen ${ }^{85}$, die zum Sammelbecken nationalkonservativer Historiker wurde. Im gleichen Jahr kam es in Mainz, mit starker Unterstützung von französischer Seite, zur Gründung des Instituts für Europäische Geschichte, das eine Abteilung für »Abendländische Religionsgeschichte« und eine für »Universalgeschichte « erhielt. Während die Leitung der letztgenannten Abteilung zunächst vakant blieb, weil der vorgesehene Mediävist Fritz Kern (1887-1950), ein Mitglied des erwähnten Arbeitskreises christlicher Historiker, kurz nach seiner Konversion zur katholischen Kirche, im Gründungsjahr verstarb, wurde der renommierte katholische Reformationsforscher Joseph Lortz (1887-1975) Direktor der Abteilung für »Abendländische Religionsgeschichte«, obwohl er als ehemaliges NSDAP-Mitglied (seit 1933) und Verfasser einschlägiger Schriften nur mühsam und mit Hilfe eines "Persilscheins« Bischof Graf von Galens entnazifiziert worden war. Mit Lortz war ein streitbarer Abendland-Ideologe gewonnen worden ${ }^{86}$.

Vor dem Hintergrund der jeweils abgesteckten Claims, der Herausbildung vor allem regional funktionierender Netzwerke, deren Existenz bis heute nachwirkt, die aber nur in Ansätzen aufgedeckt sind, wäre die These zu überprüfen, ob die "gelegentlich grotesken ${ }^{87}$ Auseinandersetzungen um die Gründung des Instituts für Zeitgeschichte erstens mit einem vollständigen Sieg der nationalkonservativen Strömung endeten und ob diese Auseinandersetzungen zweitens überhaupt jenen zentralen Stellenwert hatten, der ihnen retrospektiv häufig zugeschrieben wird. Sicherlich ist es richtig, daß angesichts der Spezifik deutscher Zeitgeschichte, $»$ im Schatten der NS-Zeit ${ }^{88}$ zu

84

85

Vgl. Manfred ASENDORF, Was weiter wirkt. Die Ranke-Gesellschaft - Vereinigung für Geschichte im öffentlichen Leben, in: 1999. Zeitschrift für Sozialgeschichte des 20. und 21. Jahrhunderts 4 (1989), S. 29-61; auf breiterer Quellengrundlage demnächst die Veröffentlichung der Studie von Amt GOEDE, Adolf Rein und die Idee der »politischen Universität« (phil. Diss.), Hamburg 2004, S. 326-368.

86 Vgl. Gabriele LAUTENSCHLÄGER, Joseph Lortz (1887-1975). Weg, Umwelt und Werk eines katholischen Kirchenhistorikers, Würzburg 1987, S. 388ff., 404ff.; vgl. dazu auch die Beiträge von Heinz DUCHHARDT und Winfried SCHULZE in diesem Band.

87

BENZ, Wissenschaft oder Alibi? (wie Anm. 59), S. 18; vgl. Hellmuth AUERBACH, Die Gründung des Instituts für Zeitgeschichte, in: VfZ 18 (1970), S. 529-555; SCHULZE, Deutsche Geschichtswissenschaft (wie Anm. 14), S. $217 \mathrm{ff}$.

88 Martin GEYER, Im Schatten der NS-Zeit. Zeitgeschichte als Paradigma einer (bundes-) republikanischen Geschichtswissenschaf, in: Alexander NÜTZENADEL, Wolfgang SCHIEDER (Hg.), Zeitgeschichte als Problem. Nationale Traditionen und Perspektiven der Forschung in Europa, Göttingen 2004, S. 25-53; vgl. Rüdiger HOHLS, Konrad JARAUSCH (Hg.), Versäumte Fragen. Deutsche Historiker im Schatten des Nationalsozialismus, München 2000 . 
stehen, die abendländisch-supranationale Strömung gute Karten gehabt hatte, dieses Institut in die Hand zu bekommen. Allerdings gab es hier offenbar keine geeigneten Bewerber von Format, Gerhard Kroll jedenfalls war es nicht ${ }^{89}$. Auf der anderen Seite ist daran zu erinnern, daß auch Gerhard Ritter seinen Kandidaten, den nationalsozialistisch belasteten und plumpen Apologeten der NS-Zeit, Michael Freund, nicht durchbringen konnte ${ }^{90}$. Hermann Mau, Schüler des Soziologen Hans Freyer und von Hermann Heimpel, der gegenüber dem Abendland-Protagonisten Karl Buchheim schließlich den Vorzug erhielt, aber nach kurzer Zeit tödlich verunglückte, war eine typische Kompromiß-Figur. Karl Buchheim, der sich in den 1950er Jahren rege in der »Abendländischen Akademie« engagierte, erhielt immerhin den Posten eines Abteilungsleiters im Institut, in dessen Gremien mit dem späteren ZDFIntendanten Karl Holzamer, Georg Stadtmüller und anderen durchaus namhafte Abendland-Streiter vertreten waren. Das Institut für Zeitgeschichte - das zeigt seine weitere Geschichte in der »Ära Rothfels - Eschenburg - Krausnick $"{ }^{91}$ - entwickelte sich nicht zur Zentrale einer Richtung, sondern ebnete die schroffen Fronten ein. Der Interpretation von Winfried Schulze in diesem Zusammenhang, es habe sich um einen "Richtungskampf innerhalb des konservativen Lagers « $^{92}$ gehandelt, ist zuzustimmen, aber dieser Richtungskampf war eben immer weniger ein existentieller Verdrängungskampf, der auch nicht mit der Niederlage der Abendland-Protagonisten endete. In die lagerüberwölbende Integrationsideologie der Adenauer-Zeit paßten sowohl die supranational-abendländische als auch die abendländisch gewendete nationalkonservative Strömung und waren im Blick auf unterschiedliche Adressaten gleichermaßen wichtig. In ihrer Gegenwartsdiagnose kamen sie zu jeweils gleichen realpolitischen Ergebnissen, nämlich der Notwendigkeit abendländischer Einheit des Westens gegen den östlichen »Bolschewismus«. In dieser Hinsicht symptomatisch war der Ort für die Jahrestagung der Ranke-

89

In der Zeit seiner interimistischen Regentschaft 1949/50 hatte er übrigens einige jüngere Abendland-Ideologen, darunter Franz Herre, mit Honoraraufträgen bedacht; AUERBACH, Gründung (wie Anm. 87), S. 550f. In seiner Darstellung der Institutsgeschichte hat Horst Möller Kroll »zweifellos beachtliche Verdienste« bescheinigt; Horst MöLLER, Das Institut furr Zeitgeschichte und die Entwicklung der Zeitgeschichtsschreibung in Deutschland, in: DERS., Udo WENGST (Hg.), 50 Jahre Institut für Zeitgeschichte. Eine Bilanz, München 1999, S. 1-68, hier S. 15 .

$90 \mathrm{Vgl}$. etwa Michael FrEUND, Geschichte ohne Distanz, in: Joachim MORAS, Hans PAESCHKE (Hg.), Deutscher Geist zwischen gestern und morgen. Bilanz der kulturellen Entwicklung seit 1945, Stuttgart 1954, S. 315-333; vgl. zum Gesamtzusammenhang CORNELISSEN, Gerhard Ritter (wie Anm. 24), S. 533ff.; zur Blamage von Ritter bei der Kommentierung von $»$ Hitlers Tischgesprächen«: ibid. S. $539 \mathrm{ff}$.

91 Hermann GRAML, Hans WOLLER, Fünfzig Jahre Vierteljahrshefte für Zeitgeschichte 1953-2003, in: VfZ 51 (2003), S. 51-87, hier S. 58ff.; vgl. Johannes HÜRTER, Hans WOLLER (Hg.), Hans Rothfels und die deutsche Zeitgeschichte, München 2005.

92 SCHULZE, Deutsche Geschichtswissenschaft (wie Anm. 14), S. 217 
Gesellschaft. Sie fand 1953 im Mainzer Institut für Europäische Geschichte statt. Gravierende konzeptionelle Differenzen lassen sich auch in einem zeitgenössischen Schlüsseldokument, dem »Handbuch politisch-historischer Bildung « der neuen Bundeswehr, nicht mehr erkennen. In dessen erstem Band unter dem Titel »Schicksalsfragen der Gegenwart«, zu dem Verteidigungsminister Franz Josef Strauß ein Geleitwort beisteuerte, schrieben unter anderen Hermann Aubin, Walter Hubatsch und Gerhard Ritter als Repräsentanten der einen ebenso wie Otto Heinrich von der Gablentz, Martin Göhring und Georg Stadtmüller als Vertreter der anderen Strömung ${ }^{93}$. Angesichtes des sich rapide vollziehenden Strukturwandels der Öffentlichkeit war es weniger entscheidend, die Kommandohöhen des Historikerverbandes erstürmt zu haben. Eine nähere Untersuchung hätte auch nicht nur die Besetzung der einschlägigen Professuren in den Universitäten, die Themenwahl für Festschriften oder die Redaktion der Fachzeitschriften einzubeziehen, sondern das weite Feld der Geschichtsvermittlung von der Tages- und Wochenpresse bis zur Schule und Erwachsenenbildung ${ }^{94}$. Dann aber verschwimmen die Kriterien für die Frage von Sieg oder Niederlage einer der beiden HistorikerStrömungen, die seit Mitte der 1950er Jahre gemeinsam in die Krise gerieten, als sich die politisch-kulturellen Rahmenbedingungen allmählich veränderten und zuerst bei jüngeren Intellektuellen ein allgemeiner Überdruß gegen abendländisches Pathos verbreitete. Das Ende des Zirkels um die »Abendländische Akademie « und "Neues Abendland» begann Mitte der 1950er Jahre und war Mitte der 1960er Jahre endgültig vollzogen ${ }^{95}$, die allgemeine Krise der nationalkonservativen, das Abendland semantisch ausnutzenden Geschichtsschreibung begann im gleichen Zeitraum mit der erbittert ausgefochtenen »Fischer-Kontroverse«, bei der die Granden der Zunft, angeführt von Gerhard Ritter, so unattraktiv »alt aussahen«, während die antiborussische Traditionsgarde daraus keinen Gewinn mehr zu ziehen vermochte ${ }^{96}$.

Schicksalsfragen der Gegenwart. Handbuch politisch-historischer Bildung, hg. vom Bundesministerium für Verteidigung. Innere Führung, Bd. 1, Tübingen 1957.

Vgl. dafür Ansätze in Wolfgang KÜTTLER, Jörn RÜSEN, Ernst ScHullN (Hg.), Geschichtsdiskurs, Bd. 5: Globale Konflikte, Erinnerungsarbeit und Neuorientierungen nach 1945, Frankfurt a.M. 1999 (ebenso die Beiträge von Gangolf HÜBNGER und Hans-Jürgen PANDEL).

Vgl. SCHILDT, Zwischen Abendland und Amerika (wie Anm. 2), S. $68 \mathrm{ff}$.

Vgl. zuletzt GrosSE KRACHT, Die zankende Zunft (wie Anm. 16), S. $47 \mathrm{ff}$. 